\title{
CHALLENGES OF INTERNATIONAL STANDARDS ON AUDITING IN GLOBAL CRISIS CONTEXT
}

\author{
Botez Daniel, Associate Professor, PhD \\ UNIVERSITY OF BACĂU
}

\section{Abstract:}

The financial crisis that broke out in summer 2007 is striking in its sheer magnitude, the speed of its contagion to the global financial sphere, as well as its persistence. These factors make it on the most impressive and unprecedented events in recent financial history.

One of key points concerning the financial crisis looking statutory audit and statutory auditors.

The financial crisis in 2001 highlighted weaknesses in the statutory audit process.

Working with the FSF and market regulators, the statutory audit profession undertook a

series of spectacular reforms with four main thrusts :

- Most countries moved from a system of self-regulation to one of shared regulation or outside regulation, most notably in the USA;

- A new system of global governance was introduced with the creation of the Public Interest Oversight Board (PIOB), which oversees the public-interest activities of the International Federation of Accountants (IFAC), particularly in the areas of audit standard-setting (International Auditing and Assurance Standards Board - IAASB) and ethics (International Ethics Standards Board for Accountants - IESBA);

- The IAASB adopted an extremely stringent standard for internal control at audit firms. The new standard provides, among other things, for a systematic concurring partner procedure before an opinion is issued. The underlying principle is that the review should make it possible to avoid large-scale audit failures by assigning a non client-facing partner to review audit work (including the identification of macroeconomic and microeconomic risks) as it is being carried out;
- Independence standards were tightened by placing stricter limits on the work done for audit clients.

Though auditors have not attracted criticism over the subprime crisis, there are continuing challenges related to the auditing profession.

Two widely use sets of auditing standards exist side by side, i.e. International Standards on Auditing (ISAs) and the US standards adopted by the Public Company Accounting Oversight Board (PCAOB). Europe should adopt ISAs as soon as possible to reduce uncertainty and promote convergence, and should call for convergence between ISAs and PCAOB standards.

Countries continue to apply different independence rules, particularly those on scope of services restrictions. Europe should seek to adopt or converge to the IFAC's independence standards when the current revision is complete.

Auditors may see their role evolving, as they report more fully on future risks faced by audited companies. However, auditors are reluctant to report publicly more fully on risk identification because of liability issues, which need to be solved. This situation may create a serious gap between the information on past events given in the audit report and expectations by the industry for a forwardlooking opinion on risks facing companies.

National supervisors and inspectors, within and outside Europe, need to develop mechanisms to cooperate more effectively at operational level in the external control of audit firms.

For Europe, one of the most important recommendation looking the process of convergence audit standards. All national 
auditing standards, including those issued by the Public Company Accounting Oversight Board (PCAOB), and should converge to International Standards on Auditing (ISAs). Statutory auditors need to report more extensively about risk identification. This will require addressing the question of auditor liability, which in many jurisdictions appears to be a major constraint to expanding the auditor's risk reporting. Convergence should also be a goal for independence standards.

Among the recommendations of the Financial Stability Forum (FSF) was that "The IAASB, major national audit standard setters and relevant regulators should consider the lessons learned during the market turmoil and, where necessary, enhance the guidance for audits of valuations of complex or illiquid financial products and related disclosures."

The IAASB had already established a task force in February 2008 to consider whether additional guidance on fair values was necessary and that task force was also asked to develop a response to the FSF recommendation. The task force includes representatives of auditors and regulators. A wider group of interested parties, including preparers and investors, has also been consulted to inform the discussions of the task force and provide feedback on activities that the IAASB could pursue in developing possible auditing guidance on fair value accounting estimates. The task force recommended that a reminder of relevant material in ISAs should be issued. This alert has been prepared in response to that recommendation.

One of the important challenges regarding Fair Value Accounting Estimates.

The following matters are particularly important for preparers and auditors in considering fair value accounting estimates:

- The measurement objective, as fair value accounting estimates are expressed in terms of the value of a current transaction or financial statement item based on conditions prevalent at the measurement date;
- The need to incorporate judgments concerning significant assumptions that may be made by others such as experts employed or engaged by the entity or the auditor;

- The availability (or lack thereof) of information or evidence and its reliability;

- The breadth of assets and liabilities to which fair value accounting may be, or is required to be, applied;

- The choice and sophistication of acceptable valuation techniques and models; and

- The need for appropriate disclosure in the financial statements about measurement methods and uncertainty, especially when relevant markets are illiquid.

Of the above, in the current environment obtaining reliable information relevant to fair values has been one of the greatest challenges faced by preparers, and consequently by auditors. The nature and reliability of information available to management to support the making of a fair value accounting estimate vary widely, and thereby affect the degree of estimation uncertainty associated with that fair value. If markets become inactive, market price information becomes unavailable and estimates need to be made on the basis of other information, often using models, some of which incorporate inputs that are "unobservable." The degree of estimation uncertainty therefore increases and affects, in turn, the risks of material misstatement. What may in the past have been a routine valuation problem may become the source of a significant risk. In such circumstances there are limits to the information that management possesses or can obtain and that therefore may be available to the auditor as audit evidence. Nevertheless, whether inputs are observable or not, preparers need to have evidence to support them, and auditors need to obtain sufficient appropriate audit evidence recognizing that the evidence may be different from what has previously been available. 
Experience to date has suggested that, while estimation of fair values has proved to be extremely difficult in light of market uncertainty, it has not proved impossible to obtain sufficient information to record these fair values in financial statements.

While fair values are commonly thought to relate primarily to financial assets and financial liabilities, the use of fair value is more widespread. Depending on the financial reporting framework, the impact of fair value accounting may be seen with regard to management's determination of pension liabilities, the value of goodwill and intangibles acquired in a business combination, real estate, endowment funds, share-based payments, non-monetary exchanges and other classes of assets and liabilities.

ISA 545 is the principal standard that is directly relevant to auditing fair value accounting estimates. It establishes standards and provides guidance on auditing fair value measurements and disclosures contained in financial statements. Fair value measurements of assets, liabilities and components of equity may arise from both the initial recording of transactions and later changes in value. Further, those financial instruments and other assets recorded at historical cost, but not required to be re-measured at fair value, may nevertheless require fair value consideration, depending on the financial reporting framework, for supplementary disclosure or for estima-tion of provisions or impairment losses. Changes in fair value measurements that occur over time may be treated in different ways under different financial reporting frameworks. For example, some financial reporting frameworks may require that such changes be reflected directly in equity, while others may require them to be reflected in income.

The ISA deals with the overarching requirement for the auditor to obtain sufficient appropriate audit evidence that fair value measurements and disclosures are in accordance with the entity's applicable financial reporting framework. Within the ISA, additional requirements tailor the requirements in other ISAs to the audit of fair value; in particular, those dealing with understanding the entity and its environment and assessing the risks of material misstatement, responding to assessed risks, using the work of an expert, obtaining management representations, and communicating with those charged with governance.

ISA 300 requires the auditor to establish the overall audit strategy for the audit. Part of the establishment of the overall strategy involves determining the characteristics of the engagement that define its scope, such as the financial reporting framework used and industry-specific reporting requirements. In the case of audits of the financial statements of banks or where there are derivative financial instruments, in addition to the ISAs, the auditor may also look to IAPS 1006 or IAPS 1012 for further guidance.

ISA 500 establishes standards and provides guidance on what constitutes audit evidence, the quantity and quality of audit evidence to be obtained, and the audit procedures that the auditor uses for obtaining that audit evidence. Unless management is able to support its valuations, it will be difficult for the auditor to obtain sufficient appropriate audit evidence. However, as evidence about assumptions and the validity of models is necessarily less reliable than evidence of a market price taken from an active market, it may be necessary to look at more sources of evidence to accumulate sufficient appropriate evidence, as the quantity of audit evidence needed is affected by the risk of misstatement (the greater the risk, the more audit evidence is likely to be required).26 For example, an auditor, or an auditor's expert, may use an independent model to compare its results with those of the model used by management in order to evaluate whether the values determined by management's model is reasonable.

In addition, the auditor may consider whether external sources provide audit evidence to which the auditor could benchmark an entity's practices. For example, sources that track provisioning by institutions may provide the auditor with evidence as to whether the 
entity's valuations are reasonable if it has invested in similar instruments.

ISA 620 establishes standards and provides guidance on using the work of an expert as audit evidence, whether the expert is used by the entity or used by the auditor. When using the work performed by an expert, the auditor is required to obtain sufficient appropriate audit evidence that such work is adequate for the purposes of the audit. ISA 620 explains that when an expert is used, the appropriateness and reasonableness of assumptions and methods used and their application are the responsibility of the expert. However, the auditor will need to obtain an understanding of the assumptions and methods used to consider whether they are appropriate and reasonable, based on the auditor's knowledge of the business and the results of other audit procedures. This guidance is supplemented by ISA 545 which includes guidance on the use of an expert and on the auditor's testing of management's significant assumptions.

ISA 260 requires the auditor to communicate audit matters of governance interest arising from the audit with those charged with governance. ISA 545 draws attention to the fact that because of the uncertainties associated with fair value measurements, the potential effect on the financial statements of any significant risks may be of governance interest. For example, the auditor considers communicating the nature of significant assumptions used in fair value measurements, the degree of subjectivity involved in the development of the assumptions, and the relative materiality of the items being measured at fair value to the financial statements as a whole. In addition, the need for appropriate controls over commitments to enter into financial instrument contracts and over the subsequent measurement processes are matters that may give rise to the need for communication with those charged with governance.

Certain audit matters of governance interest are likely to be of interest to banking supervisors, particularly when those matters may require urgent action by the supervisor. In many countries, requirements concerning the auditor's communication to banking supervisors are established by law, by supervisory requirement or by formal agreement or protocol. In situations where there are no such requirements, agreements or protocols, the auditor encourages the bank's management or those charged with governance to communicate on a timely basis matters that, in the auditor's judgment, may be of urgent interest to the banking supervisor.

ISA 240 requires the auditor to consider the risks of material misstatements in the financial statements due to fraud. At times of market instability, unexpected losses may arise through failure to protect the entity from extreme fluctuations in commodity prices, from unanticipated weakness in asset prices, through trading misjudgments, or for other reasons. In addition, financing difficulties create pressures on management who are concerned about the solvency of the business. Such circumstances may give rise to incentives to engage in fraudulent financial reporting: to protect personal bonuses, to hide management error, to avoid breaching borrowing limits or to avoid reporting catastrophic losses.

Fraudulent financial reporting often involves manage-ment override of controls that otherwise may appear to be operating effectively. This may include inappropriately adjusting assumptions and changing judgments used to estimate account balances, for example using assumptions for fair value accounting estimates that are inconsistent with observable marketplace assumptions. In illiquid markets, the increased use of models and lack of market comparisons may present opportunities for manipulation or override of amounts calculated by brokers or experts. Even without fraudulent intent, there may be a natural temptation to bias judgments towards the most favorable end of what may be a wide spectrum. What is favorableis not always the position leading to the highest profit or lowest loss. 
In auditing fair value accounting estimates, therefore, the auditor may need to consider whether the circumstances give rise to increased fraud risks. In reviewing the judgments and decisions made by management in the making of fair value accounting estimates, the auditor may identify indicators of possible management bias; if this is the case, the auditor may need to consider the implications for the rest of the audit.

ISA 700 requires the auditor to evaluate the conclusions drawn from the audit evidence obtained as the basis for forming an opinion on the financial statements. Forming an opinion as to whether the financial statements give a true and fair view or are presented fairly, in all material respects, in accordance with the applicable financial reporting framework also involves evaluating the fair presentation of the financial statements. In doing so, the auditor considers whether the financial statements, including the note disclosures, faithfully represent the underlying transactions and events in the context of the financial reporting framework.

In certain circumstances, the auditor may determine that there is a need to draw the reader's attention to a significant uncertainty by adding an Emphasis of Matter paragraph to the auditor's report. ISA 701 describes the manner in which this would be done. ISA 701 describes an uncertainty as "a matter whose outcome depends on future actions or events not under the direct control of the entity but that may affect the financial statements." This, strictly, does not describe the type of estimation uncertainty that affects fair value measurements. Nevertheless, as indicated above, in times of uncertainty the disclosures about fair values in the financial statements may assume particular importance. However, any such emphasis is not an alternative to modification of the auditor's opinion if the auditor is not able to obtain sufficient appropriate audit evidence or disagrees with the treatment of fair values in the financial statements.

In conjunction with its Clarity project, the IAASB revised a number of its standards including ISA 540, "Audit of Accounting Estimates" (ISA 540). The similarity in the audit approaches to estimates and fair value measurement led to a decision to combine ISA 540 with ISA 545, "Auditing Fair Value Measurements and Disclosures" (ISA 545), thereby revising both standards. The IAASB believes that the combination enhances the distinction between estimates involving fair value measurement and other types of estimates because it draws upon the similarities between the two while contrasting their subtle differences. The revised ISA, ISA 540 (Revised and Redrafted), places more emphasis on areas of higher risk, accounting judgment, and possible bias, thereby assisting the auditor to form appropriate conclusions about the reasonableness of estimates in the context of an entity's financial reporting framework. These are also areas of particular importance in the context of fair values.

The revised ISA also includes expanded guidance on auditing fair value accounting estimates as compared with extant ISA 545, including audit considerations relating to the proper application of the requirements of the financial reporting framework relevant to such estimates and the use of models in valuations.

ISA 540 (Revised and Redrafted) highlights matters such as the auditor's evaluation of the effect of estimation uncertainty on risk assessments, management's methods for making estimates, the reasonableness of assumptions used by management, and the adequacy of disclosures. Such matters are relevant to estimates in general, but are also particularly important in the context of fair values.

ISA 540 (Revised and Redrafted) will be effective for audits of financial periods commencing on or after December 15, 2009, the date when all the standards redrafted under the IAASB's Clarity project become effective.

This may particularly be the case, for example, when auditors are faced with circumstances in which the financial instruments the entity has invested in have relatively high estimation uncertainty. These may include fair value accounting estimates 
for complex financial instruments in general, derivative financial instruments not publicly traded, and fair value accounting estimates for which a highly specialized entity-developed model is used or for which there are assumptions or inputs that cannot be observed in the marketplace.

\section{References:}

[1]. www.ifac.org 